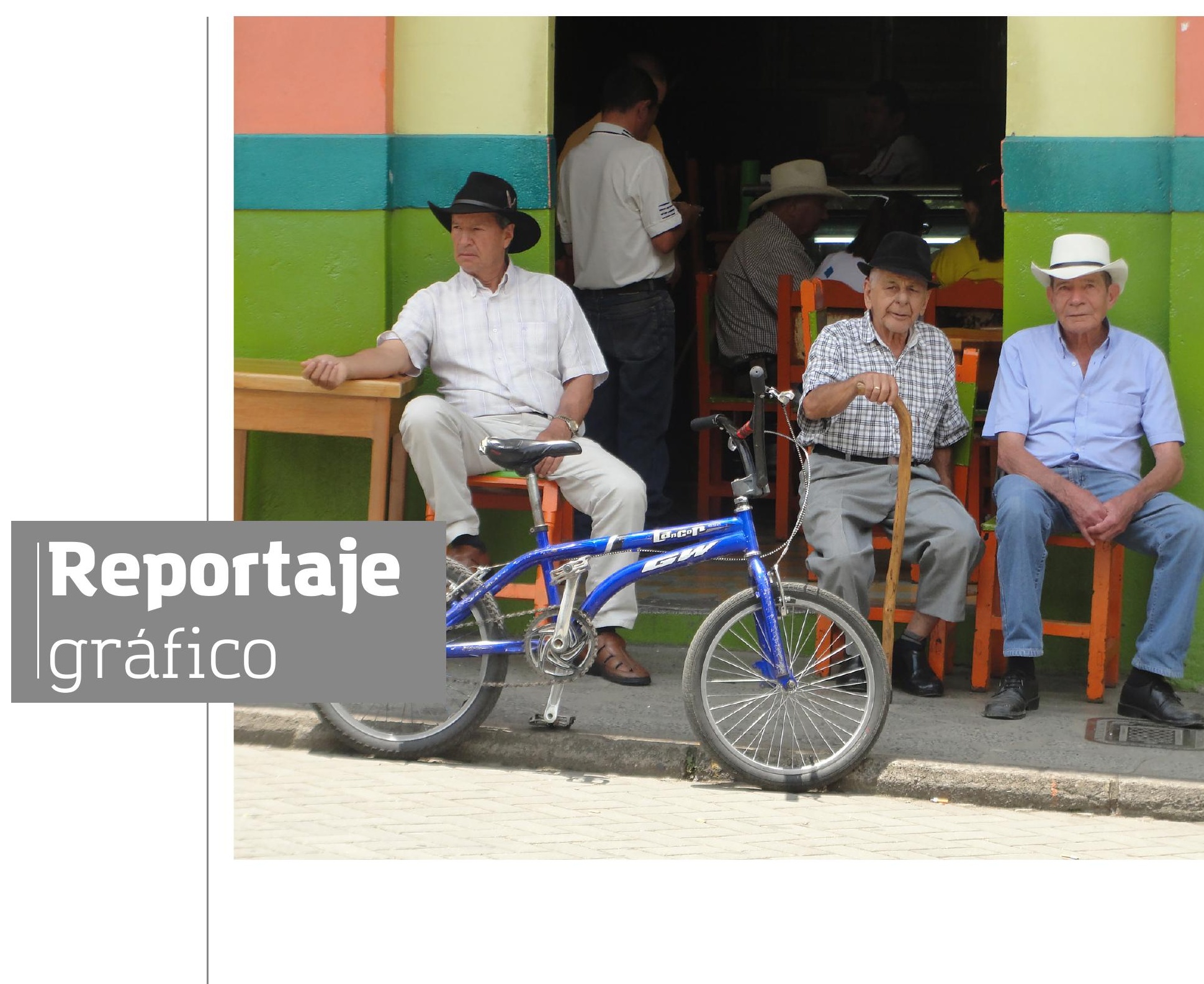




\section{Camiones de escalera: cultura popular rodante}

Comunicación

número 44

Enero-junio

2021 | pp. $140-149$

\section{María Isabel Zapata Cárdenas}

Comunicadora social-

periodista y magister en

Comunicación Digital de

la Universidad Pontificia

Bolivariana (UPB). Profesora

e investigadora de la

Facultad de Comunicación

de la Universidad de

Medellín. Candidata a

doctora en Educación y

Comunicación Social de la

Universidad de Málaga.

mariaz@uma.es

https://orcid.org/0000-

0002-6554-176X
Detrás de su decorado, de sus nombres de pila y de sus colores, hay familias y generaciones dedicadas a mantener una actividad que va más allá del sector transportista y que reconocen como vocación heredada. Propietarios, conductores, decoradores, alistadores y carroceros: todos al unísono perfeccionan un trabajo artesanal. No hay escuelas ni ensambladoras industriales: solo la labor de generaciones que entregan el legado al interesado. Y algunos ya creen que la extinción del sistema de transporte y sus protagonistas es una amenaza latente.

Estas imágenes forman parte del registro visual que acompaña la investigación doctoral Análisis iconográfico de la cultura popular campesina colombiana. Caso: camiones de escalera. Relatos e historias mediadas por la imagen, presentada por la investigadora antioqueña María Isabel Zapata Cárdenas, adscrita el doctorado en Educación y Comunicación Social de la Facultad de Ciencias de la Comunicación de la Universidad de Málaga, en España.

Los camiones de escalera son un ejemplo de las manifestaciones campesinas populares que por décadas se han desplazado por las vías encumbradas, montañosas y rurales del territorio colombiano. Sus colores, denominaciones, decorados, sonidos al rodar demuestran la carga inmaterial y subjetiva de propietarios y conductores. Cada vehículo es un universo individual con elementos propios. No hay similitudes entre camiones. Son obras de arte popular rodantes. Muchos de ellos llevan los nombres de los primeros 
amores o de sus antiguos dueños: La Colegiala, La 60, La Bola de Soldadura, El Girasol, El Rey de Reyes.

El Suroeste antioqueño es reconocido por su alta producción cafetera, pero también por inscribir el único acuerdo municipal de protección cultural y patrimonial en Colombia: es el Acuerdo 015 del 3 de marzo de 2004, del municipio de Andes. Los camiones de escalera de este municipio son cuidados y admirados por propios y visitantes. Una preocupación que les ha permitido mantener activo el sistema de transporte mientras que sus vehículos son reconocidos por el buen estado de conservación. En la actualidad hay más de 50 camiones activos en el municipio andino.

En cuanto a su riqueza visual, la geometría plana y sus formas especiales son reconocidas en todas las franjas y laterales que componen sus paredes. Por ejemplo, las escaleras antioqueñas tienden a identificarse por la gran cantidad de dibujos hechos a base de compás y regla, todo un trabajo de precisión en el trazo. En Caldas, Risaralda y Cauca tienen menos iconografía y geometría, y dejan espacios libres y vacíos para que el color de la pintura sobresalga como protagonista central. Es común encontrar en sus decorados expresiones como la estrella de David, rombos, flores geométricas de 12, 24 y 32 pétalos, circunferencias, estrellas decagonales, triángulos, entre otros.

En cualquier caso, no hay dos camiones iguales: cada carro es una obra rodante de gráfica popular, en la que cada dueño, conductor y decorador expresa sus gustos en las superficies de la chiva.

Estos vehículos se rigen por las manifestaciones culturales de los territorios por donde transitan. Las devociones religiosas populares, las intervenciones artísticas, la reinterpretación y la mezcla ecléctica de los íconos tradicionales con el consumo moderno se evidencian en el interior y exterior de un camión de escalera. Las duplas visuales entre íconos religiosos y escudos de equipos de fútbol, refranes y dichos populares y recomendaciones de seguridad para el recorrido son algunas de las simbiosis que se observan dentro de estos carros. Además, las fotografías de los seres amados, el personaje de farándula admirado y hasta los títulos de canciones queridas amenizan los viajes.

Hay que aclarar que el nombre de este vehículo cambia según la región. En la zona Andina son conocidos como camiones, berlinas o líneas. En el Suroeste son líneas. En el Caribe y el sur del país son chivas, término además usado también en las ciudades capitales, donde tienen otros usos comerciales diferentes al transporte de carga y pasajeros. 
Para este proceso de investigación fueron elegidos 33 camiones de escalera del Suroeste (municipios de Andes y Jardín) y del Oriente (Guarne) de Antioquia, por los estados de conservación y el interés por describir la cotidianidad campesina que rueda por las vías terciarias de sus localidades.

Las imágenes presentadas son referentes detallados de partes específicas de los vehículos, que se exaltan por su complejidad gráfica, además de las conexiones que se gestan desde "los colores montañeros", como los define el decorador Alejandro Serna, de Andes; además de los registros de algunos conductores y propietarios de estos viejos sistemas híbridos de carrocerías y motores que se niegan a dejar de prender y rodar. Un trabajo visual enmarcado en la cultura y la gráfica popular campesina de Antioquia. Geometría y paleta de colores de un camión de escalera. Abril 12 de 2018. 
La Bola de Soldadura: un camión modelo Ford de 1964. Transita entre los municipios de Andes,

Ciudad Bolívar y Jericó. Abril 16 de 2019

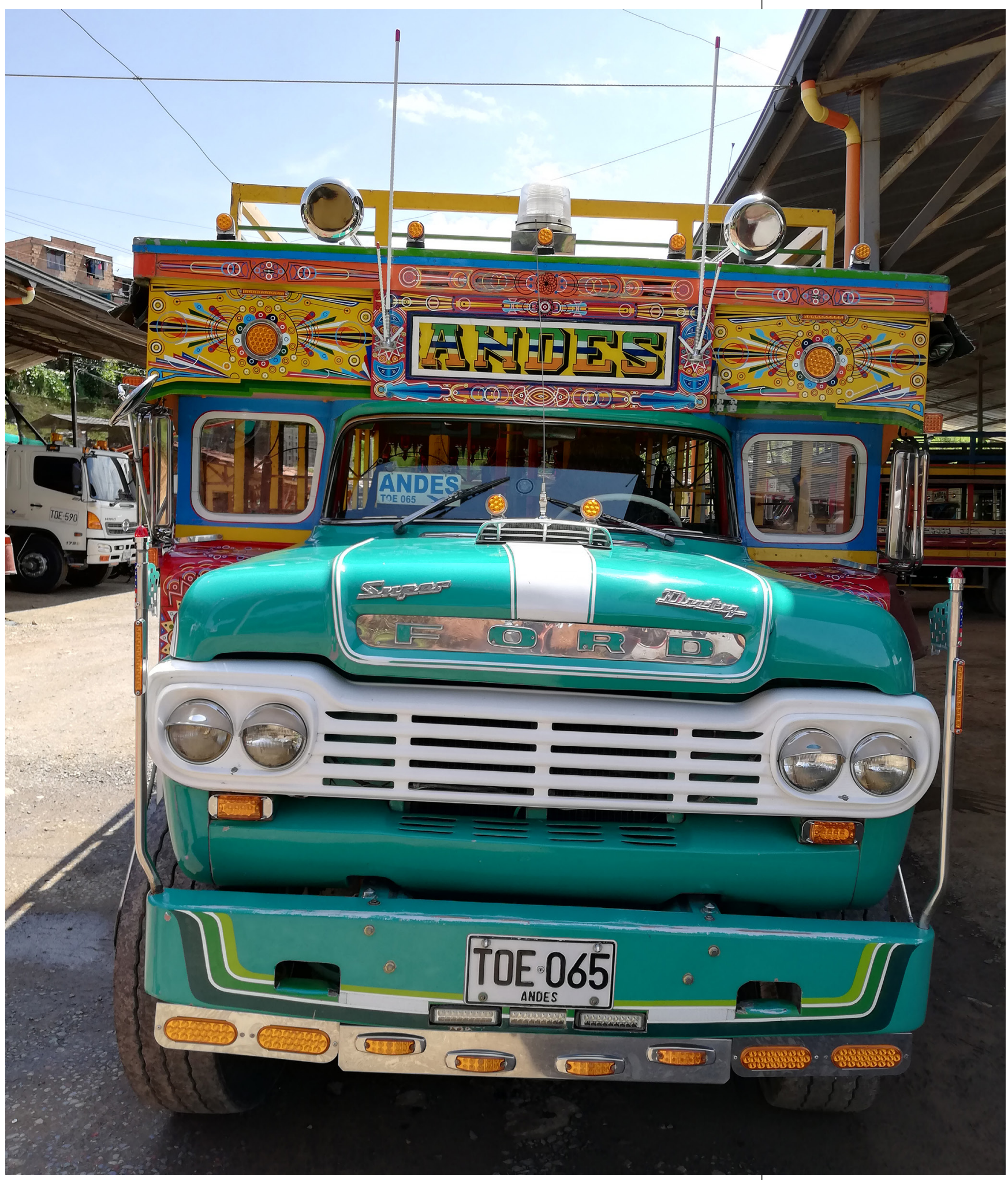


El motor de La 60, camión de escalera del municipio de Jardín.

Por dentro y por fuera son cuidados y preservados. Abril 10 de 2019

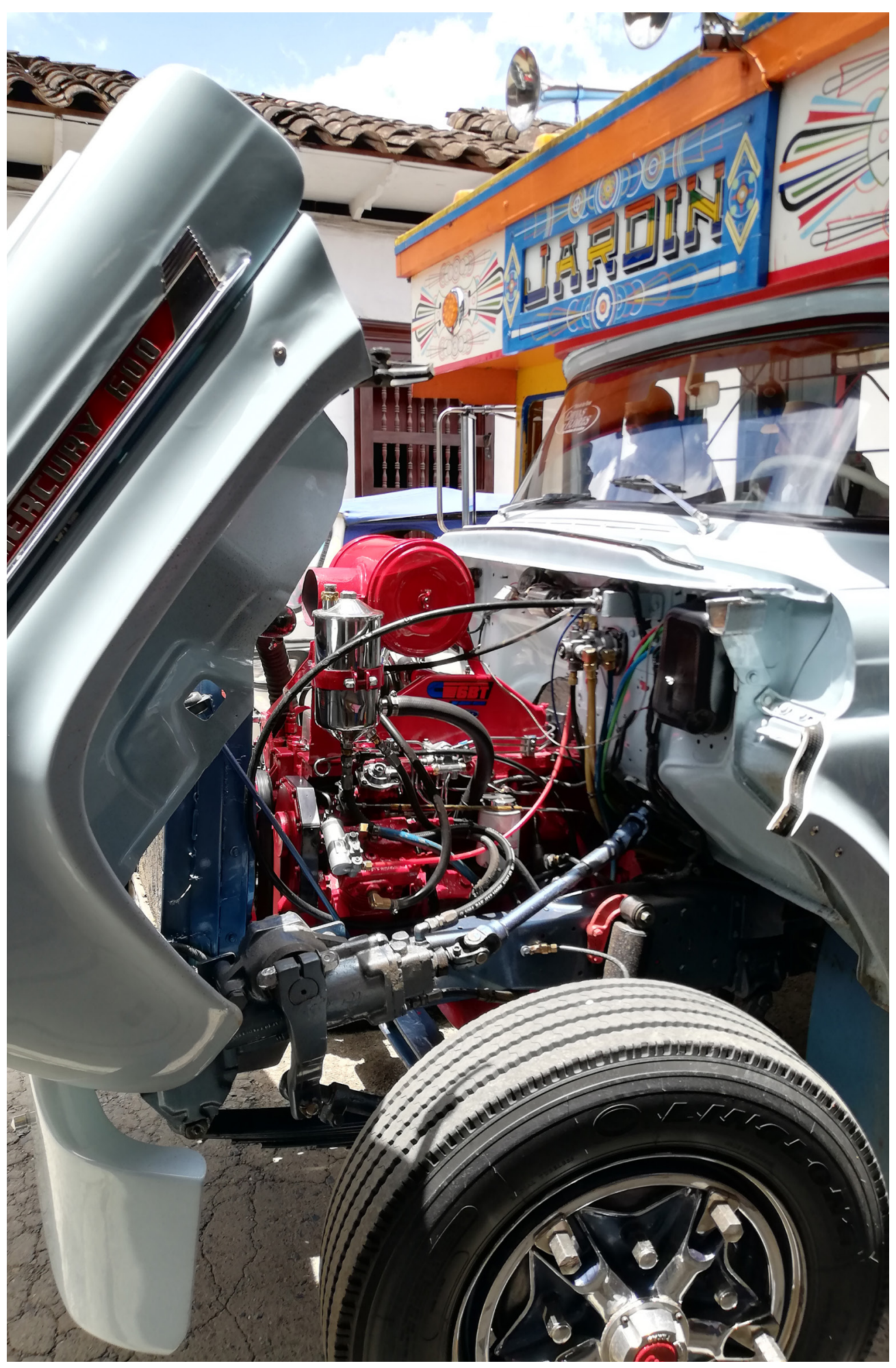


Los colores inspirados en el paisaje forman parte de la unidad cromática de los vehículos. Abril 14 de 2019.

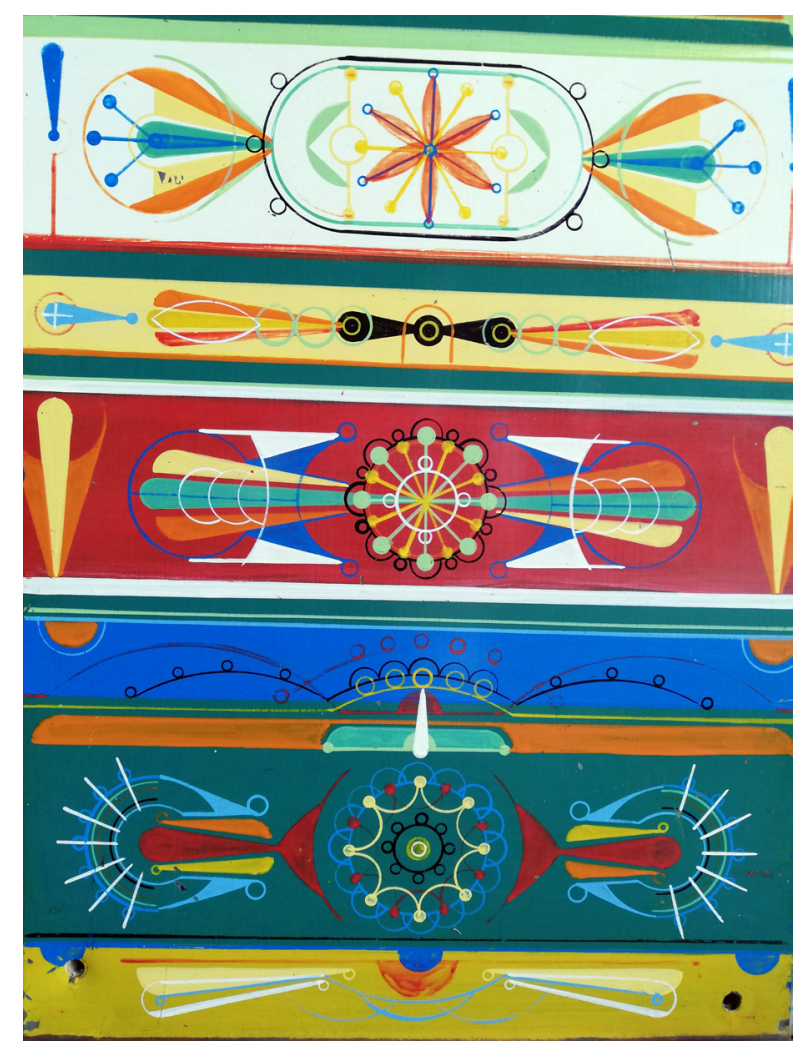

Comunicación

número 44

Enero-junio

2021

El bisel (carnero) es un elemento característico y valorado entre los propietarios de los camiones de escalera. Vehículo: El Girasol. Abril 9 de 2019.

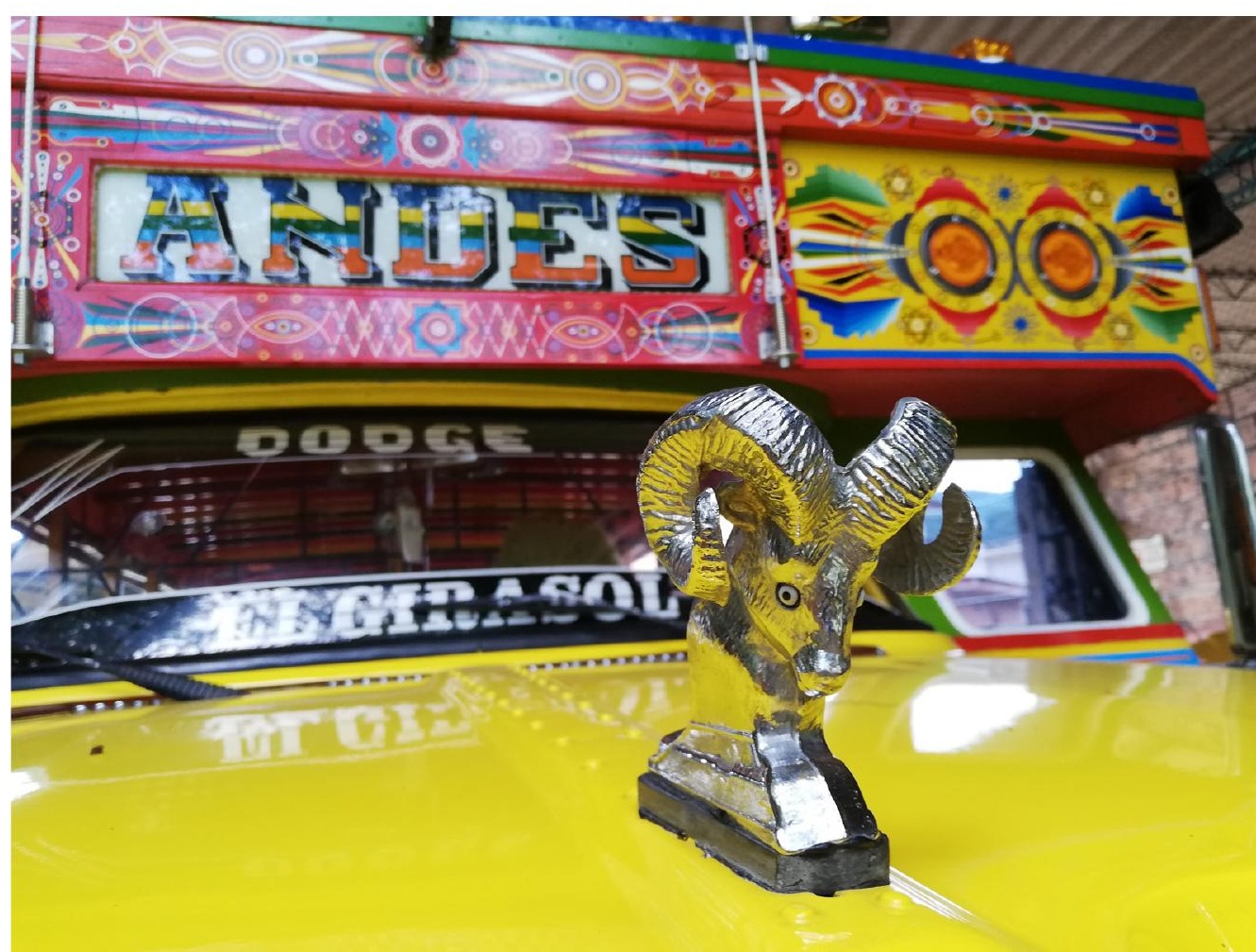



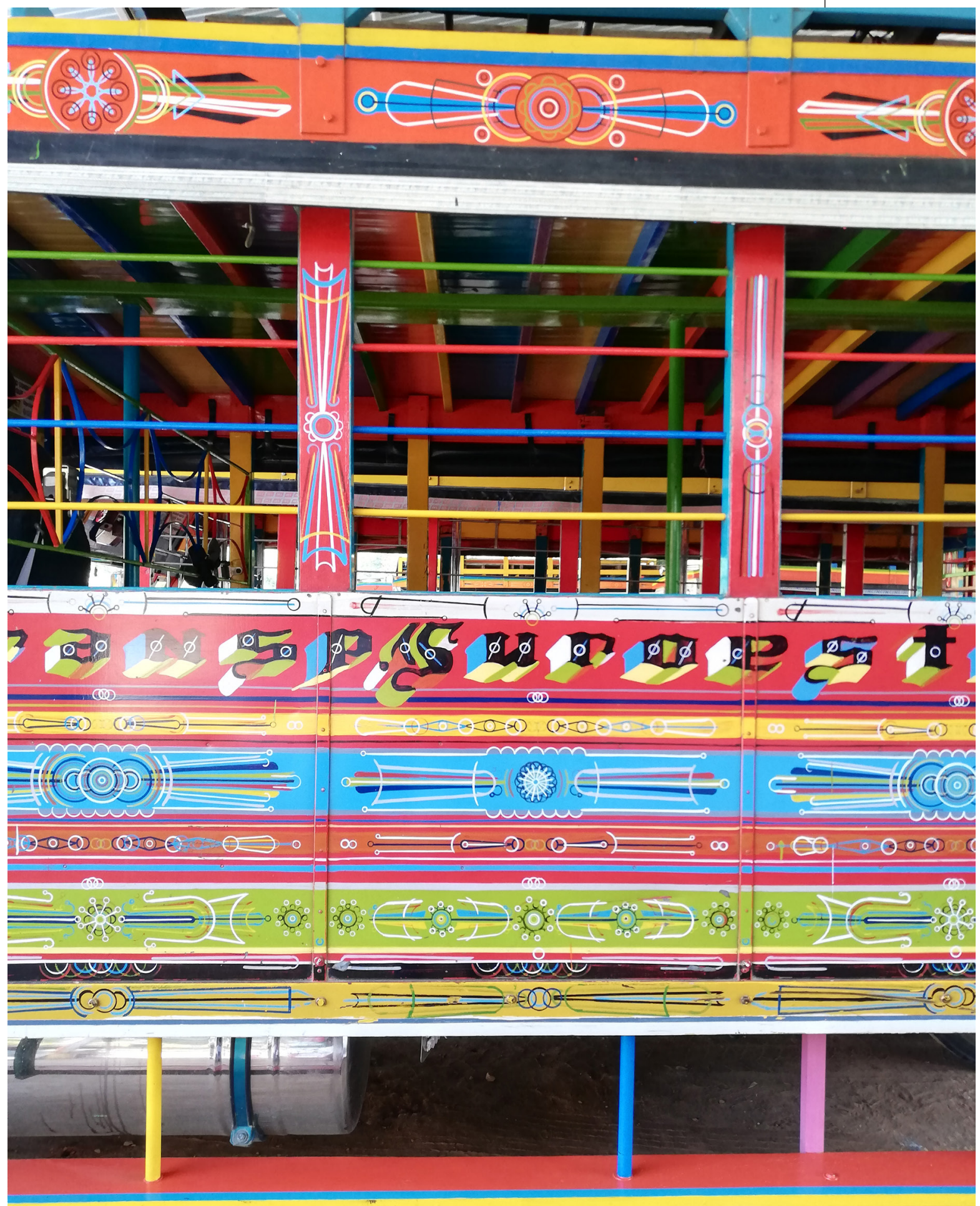
comunicación

número 44

Enero - junio

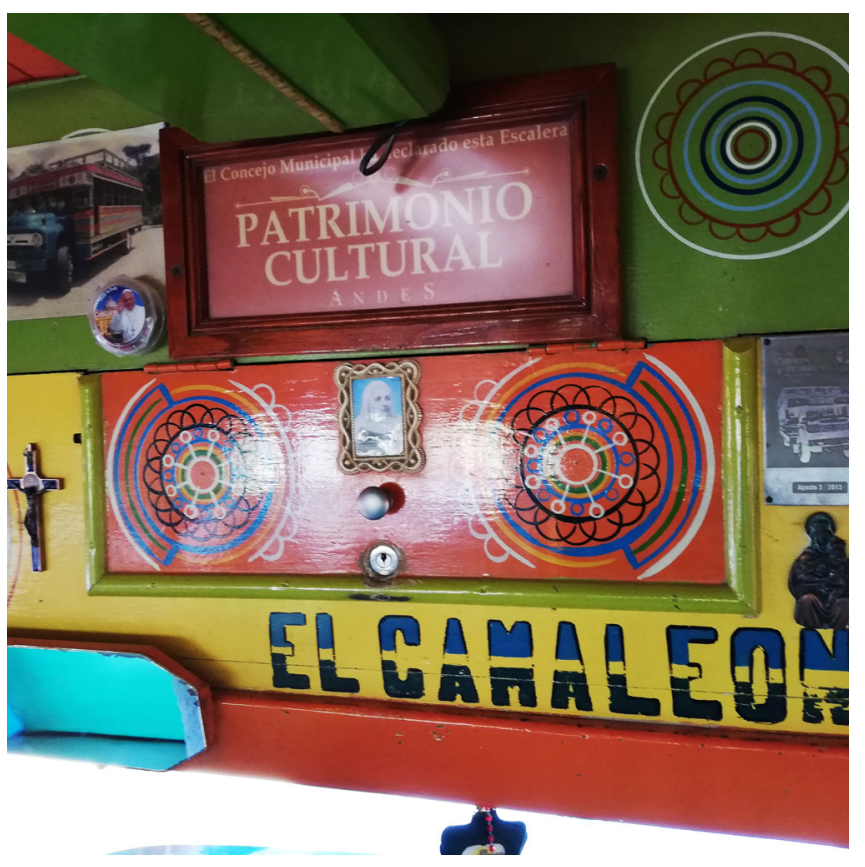

Platina protectora intervenida con las formas y figuras propuestas. Protege la vida de las llantas en los caminos complejos. Abril 11 de 2019.

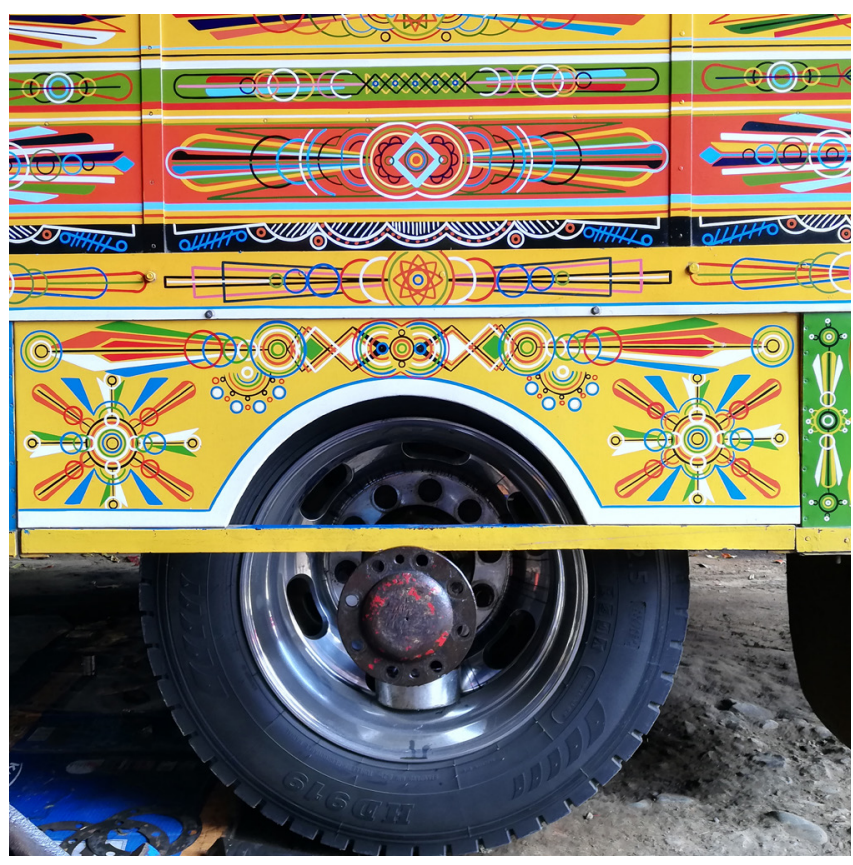


comunicación

número 44

Enero-junio

De izquierda a derecha superior: decorador (Alejandro Serna Quintero), conductor (el Muelón, Jorge Hernán Ramírez García), propietario y conductor (Frijoles, Jorge Humberto Restrepo) y conductor (Édgar de Jesús Restrepo Restrepo). Abril 11 de 2019.

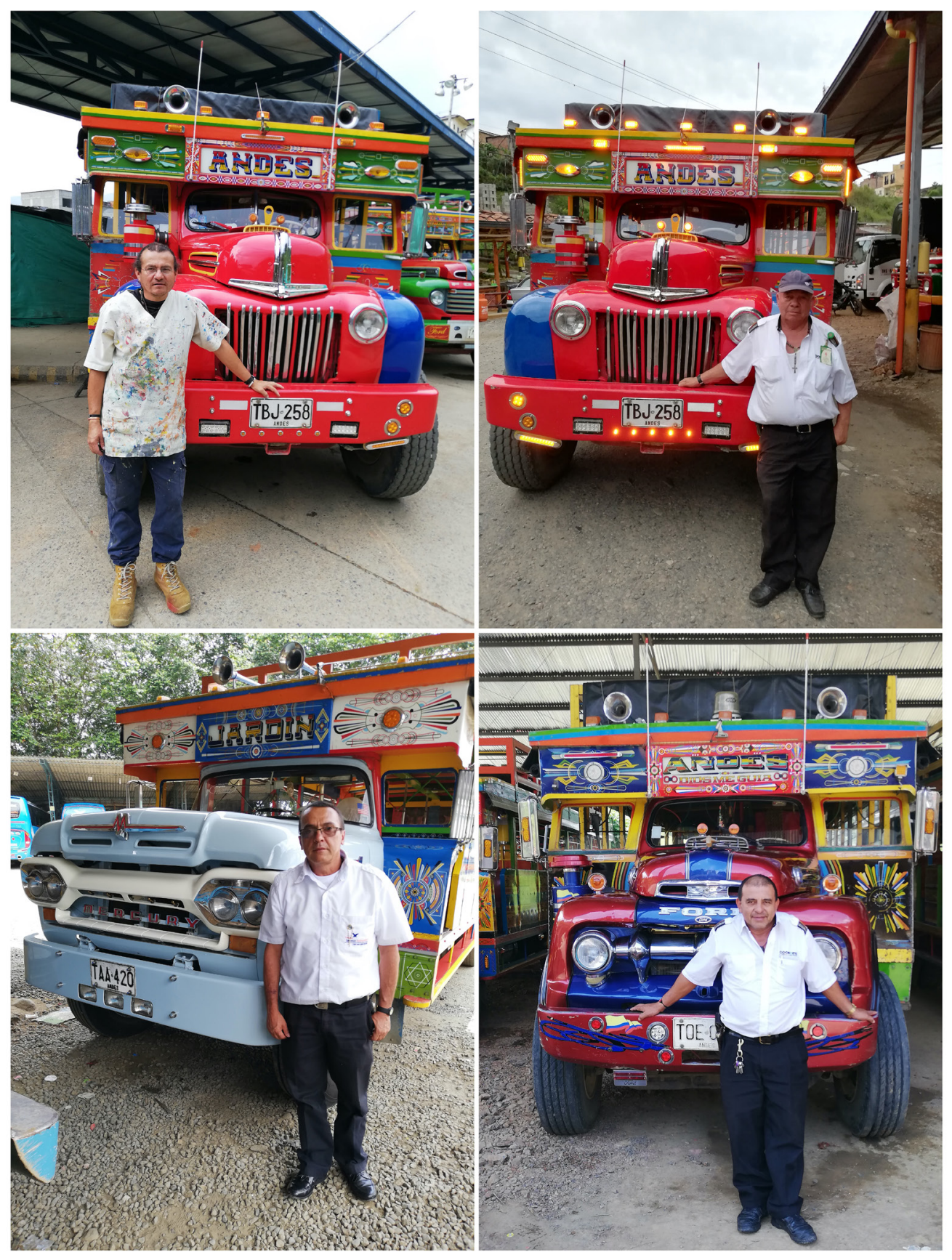

